\title{
TEST YOURSELF
}
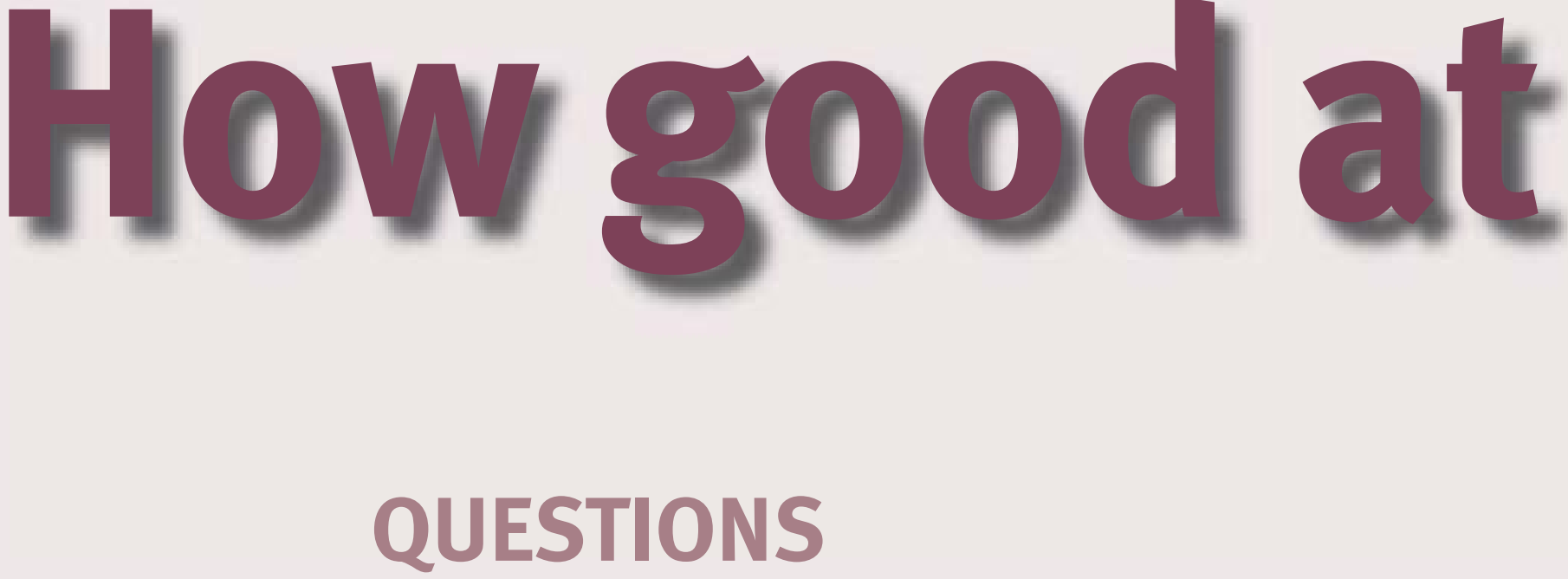

1. Consider the following case.

The following brain scans were taken on a young male with somnolence and irritability. What is the diagnosis?

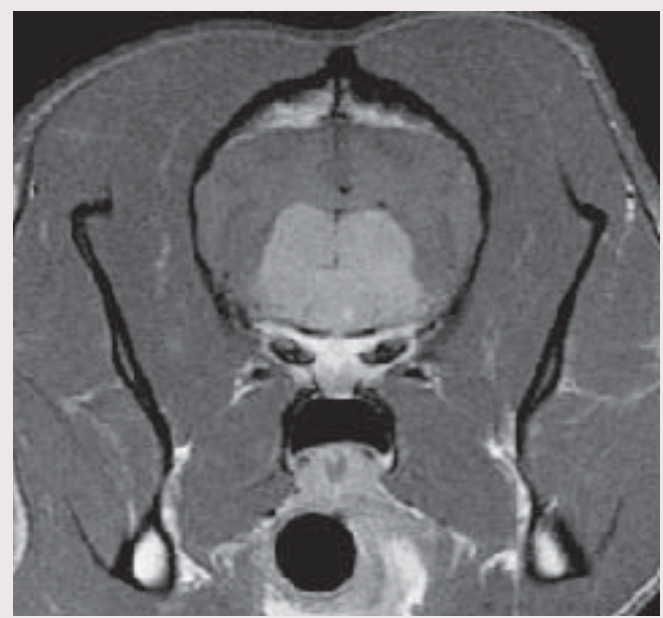

2. With regards to Susac's syndrome, are the following statements true or false:

(a) It is due to an inflammatory micro-angiopathy.

(b) It is a monophasic illness.

(c) High frequency hearing loss is typical.

(d) Hyperfluorescence of retinal arterioles is seen on fluorescein angiography.

(e) Oligoclonal bands are usually seen in the CSF.

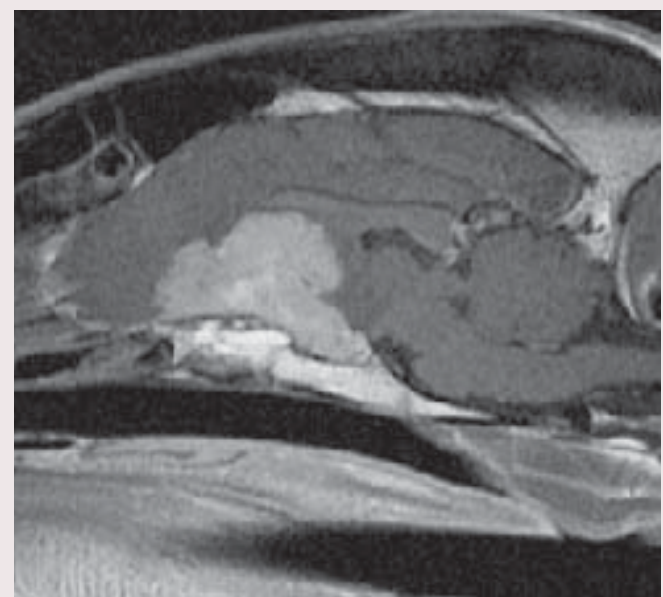

Figure 1 (a) T1 post gadolinium enhanced coronal MR image. (b) T1 post gadolinium enhanced sagittal MR image. Case and images courtesy of Dr John Hesselink, http://spinwarp.ucsd. edu/NeuroWeb, with permission. 
